\title{
Inflamatuvar barsak hastalıklarında tromboz sıklığı ve trombozun hastalık seyrine olan etkisi
}

The frequency of thrombosis in inflammatory bowel disease and the effect of thrombosis on the course of the disease

Muhammet Yener AKPINAR, Yasemin ÖZDERIN ÖZIN, Zeki Mesut Yalın KILIÇ, İsmail Hakkı KALKAN, Mahmut YÜKSEL, İlyas TENLIK, Fatih SAYGILI, Özlem AKDOĞAN, Mustafa KAPLAN, Ertuğrul KAYAÇETIN

Türkiye Yüksek Ihtisas Eğitim ve Araştırma Hastanesi, Gastroenteroloji Kliniği, Ankara

Giriş ve Amaç: Normal popülasyona göre inflamatuvar barsak hastalığının tromboz riskinde artışla beraber olduğu iyi bilinir. Biz burada ülseratif kolit ve Crohn hastalığı olan hastalarımızda tromboz sıklığını, tromboz saptanan hastaların klinik seyirlerini ve trombozların özelliklerini belirlemeyi amaçladık. Gereç ve Yöntem: Türkiye Yüksek Ihtisas Eğitim ve Araştırma Hastanesi Inflamatuvar Barsak Hastalıkları polikliniğinde takip edilen 3128 hasta tromboz yönünden retrospektif olarak incelendi. Bulgular: Çalışmamıza toplam 20 hasta alınd. Hastaların yaş ortalaması 40,45 (22-70) olup 16 hasta erkek, 4 hasta kadındı. Hastalarımızın 10 tanesinde tromboz bacak derin venlerinde iken 4 hastada bacak derin venleriyle beraber pulmoner emboli şeklinde görüldü. 2 hastada tromboflebit, 1 hastada serebral ven trombozu, 1 hastada mezenterik ven trombozu ve 2 hastada da portal ve hepatik ven trombozu olarak görüldü. Ilk inflamatuvar barsak hastalığı tanısı ile ilk tromboz tanısı arası geçen süre ortanca 16 ay (2-240)'d1. Trombozlar 15 hastada aktif hastalık esnasında oluşmuştu. 20 hastanın 13 tanesinde tromboz tanısı sonrası aldıkları medikal tedavilerde bir üst basamağa geçiş görüldü. Sonuç: Inflamatuvar barsak hastalığı tromboza zemin hazırlayan bir hastalıktır. Tromboz gelişen hastaların erken tanı ve tedavisi morbidite ve hatta mortalitede azalmaya neden olacaktır. Tromboz ciddi seyredecek inflamatuvar barsak hastalığının habercisi olabilir. Aktif hastalık özellikle pretombotik bir durum olarak değerlendirilmeli ve gerekli antikoagülasyon başlanmalıdır.

Anahtar kelimeler: Inflamatuvar barsak hastalı̆̆ı, ülseratif kolit ve Crohn hastalı̆̆, tromboz

\section{GİRISs}

Inflamatuvar barsak hastalıkları (IBH) kronik inflamasyonla karakterli hastalıklardır. Bu hastalıklar primer olarak barsakları etkilese de bir çok barsak dışı organ ve sistemi de etkilemektedir (1). Trombozlar İH'nın iyi bilinen vasküler manifestasyounudur. Klinik çalışmalarda \%1,3-7 arasında bildirilen sıklığı otopsi çalışmalarında \%39'lara ulaşmaktadır $(2,3)$. Normal popülasyona göre IBH'nın tromboz riskinde artışla beraber olduğu iyi bilinir (4). IBH'da hastalık ilişkili faktörlerin trombozlarla ilişkisini araştıran farklı çalışmalara literatürde rastlanabilir. Biz burada ülseratif kolit (ÜK) ve Crohn Hastalığı $(\mathrm{CH})$ olan hastalarımızda tromboz sıklığını, tromboz saptanan hastaların klinik seyirlerini, trombozların özelliklerini belirlemeyi amaçladık.

\section{GEREC ve YÖNTEM}

Türkiye Yüksek İhtisas Eğitim ve Araştırma Hastanesi Gastro-
Backgrounds and Aims: Inflammatory bowel disease increases the risk of thrombosis. Here we have present our patients with ulcerative colitis and Crohn's disease having thrombosis, their clinical course, and the properties of thrombosis in these patients. Materials and Methods: A total of 3.128 patients who were followed up in the Türkiye Yüksek Ihtisas Training and Research Hospital Inflammatory Bowel Disease Department were investigated for thrombosis. Results: Of the total, 20 patients with thrombosis were included in the study. The median age of the patients was 40,45 (22-70 years). Of these, 16 patients were men and 6 were women. Thrombosis was diagnosed in deep veins in 10 patients. In addition, 4 patients were diagnosed with pulmonary emboly with deep vein thrombosis, 3 thrombophlebitis, 1 with cerebral vein thrombosis, 1 with mesenteric vein thrombosis, and 2 with portal and hepatic vein thrombosis. The median time between the first inflammatory bowel disease diagnosis and the thrombosis diagnosis was 16 months (2-240). Thrombosis was diagnosed in 15 patients while they were in the active phase of their disease. The treatment of 13 patients was upgraded during their clinical course. Conclusion: Inflammatory bowel disease is a thrombophilic condition. An early diagnosis and appropriate treatment of these patients are essential in order to reduce morbidity and mortality. Thrombosis may predict severe disease. An active disease must be considered as a pre-thrombotic situation, and prophylactic anticoagulation must be integrated within the treatment.

Key words: Inflammatory bowel disease, ulcerative colitis, Crohn's disease, thrombosis

enteroloji Bölümü Inflamatuvar Barsak Hastalıkları polikliniğinde takip edilen 3.128 hasta retrospektif olarak incelendi. Hastaların vizite verdikleri bilgilerden ve hasta dosyalarından özgeçmişlerinde tromboz hikayesi olan hastalar toplandi. Tromboz hikayesi olan hastaların bilgileri ulaşılabildiyse hastaların kendilerinden, hasta dosyaları ve hastane otomasyon sisteminden elde edildi.

\section{BULGULAR}

Çalışmamıza toplam 20 hasta alındı. Hastaların yaş ortalamasi 40,45 (22-70) olup 16 hasta erkek, 4 hasta kadındı. Hastaların 10 tanesinde ÜK varken 10 hastada $\mathrm{CH}$ izlendi. Ortalama hastalık süresi 113,8 ay (26-292)'dı. Crohn hastalarında fenotipik özelliklere bakıldığı zaman 4 hasta striktüran, 4 hasta inflamatuvar fenotipteyken 2 hastada perianal hastalık vardı. Crohn hastalarında tutulum yeri 4 hastada ileokolit, 5 
hastada kolit ilen 1 hastada ileit şeklindeydi. Ülseratif kolitli hastaların 3 tanesi sol tutulumlu iken 7 hastanın ekstensif tutulumu vardı. Komorbid hastalıklara bakıldı ğı zaman 20 hastanın sadece bir tanesinde diyabetes mellitus, bir tanesinde ise primer sklerozan kolanjit vardı. Hastaların 8 tanesi hiç sigara içmemişken 4 hasta aktif içiciydi, 8 hasta ise sigara içmeyi bırakmıştı. Tüm hastalar içinde 7 hasta cerrahi müda-

\begin{tabular}{|c|c|}
\hline Değişkenler & Sayı \\
\hline Hasta Sayısı & 20 \\
\hline Yaş & $40,45(22-70)$ \\
\hline Cinsiyet (erkek/kadın) & $14 / 6$ \\
\hline IBH tipi (ülseratif kolit/Crohn hastalığı) & $10 / 10$ \\
\hline Hastalık süresi (ay) & $113,8(26-492)$ \\
\hline Ilk tanı-Tromboz tanısı arası süre (ay) & $26(2-240)$ \\
\hline \multicolumn{2}{|l|}{ CH fenotipi } \\
\hline Inflamatuvar & 4 \\
\hline Striktüran & 4 \\
\hline Perianal hastalık & 2 \\
\hline \multicolumn{2}{|l|}{$\mathrm{CH}$ tutulum paterni } \\
\hline Ileokolit & 4 \\
\hline Kolit & 5 \\
\hline Ileit & 1 \\
\hline
\end{tabular}

ÜK tutulum paterni

Distal tip 3

Ekstensif tip 7

Cerrahi Öyküsü 7

Tedavi

Tromboz tanısı esnasında

5-ASA 13

Azatiyopürin 3

Steroid

Anti-TNF

1

Ilaç yok

Güncel Tedavi

5-ASA

Azatiyopürin

10

Steroid

Anti-TNF

Diğer (UDCA)

Mortalite

1

UDCA: Ursodeoksikolik asit, anti-TNF: Anti tümör nekrozis faktör, ÜK: Ülseratif kolit, CH: Crohn hastalığı 5-ASA: 5-amino salisilik asit hale geçirmişti. Mortalite mezenterik ven trombozu gelişen bir hastada izlendi (Tablol).

Hastalarımızın 10 tanesinde tromboz bacak derin venlerinde iken 4 hastada bacak derin venleriyle beraber pulmoner emboli şeklinde görüldü. 2 hastada tromboflebit, 1 hastada serebral ven trombozu, 1 hastada mezenterik ven trombozu ve 2 hastada da portal ve hepatik ven trombozu olarak görüldü (Şekil 1). Ilk IBH tanısı ile ilk tromboz tanısı arası geçen süre ortanca 16 ay (2-240)'dl. Trombozlar 15 hastada aktif hastalık esnasında oluşmuştu. 1 hasta tromboz geliştiği esnada remisyondayken 4 hastada hastalık aktivasyonu değerlendirilemedi. Trombozların seyrine bakıldığında 13 hastada akut olup düzeldiği görülürken 6 hastada kronik hale geldiği görüldü. Bir hasta ise bu çalışma yapılırken takip altında ol-

Tablo 2. Tromboz lokalizasyonları, uygulanılan tedaviler ve tromboz sonrası hastaların ilaç değişimi.

\begin{tabular}{|lc}
\hline Değişkenler & Sayı \\
Tromboz tipi & \\
DVT & 10 \\
DVT ve pulmoner emboli & 4 \\
$\quad$ Tromboflebit & 2 \\
$\quad$ Mezenterik ven trombozu & 1 \\
$\quad$ Serebral venöz tromboz & 1 \\
$\quad$ Hepatik ve portal ven trombozu & 2 \\
\hline Tromboz süresi(akut/kronik) & $13 / 6$ \\
\hline Tromboz için aldığı antikoagülasyon & 9 \\
\hline DMAH & 8 \\
\hline Warfarin & 1 \\
\hline Rivaroksaban & 2 \\
\hline Değerlendirilemedi & 2,75 (1-120) \\
\hline Antikoagülasyon tedavi süresi (ay) & 15 \\
\hline Tromboz esnasında hastalık aktivasyonu & 1 \\
\hline Aktif & 4 \\
\hline Remisyonda & \\
\hline Değerlendirilemedi & \\
\hline
\end{tabular}

Tromboz tanısı sonrası tedavi modifikasyonu

Tedavi upregülasyonu 13

Tedavide değişim yok 5

Değerlendirilemedi

2

Tromboz-cerrahi ilişkisi

Tromboz cerrahiden önce $\quad 2$

Tromboz cerrahiden sonra 4

Değerlendirilemedi 1

Antikoagülan altında GIS kanama $\quad 0$

DMAH: Düşük molekül ağırlıklı heparin, DTV: Derin ven trombozu 


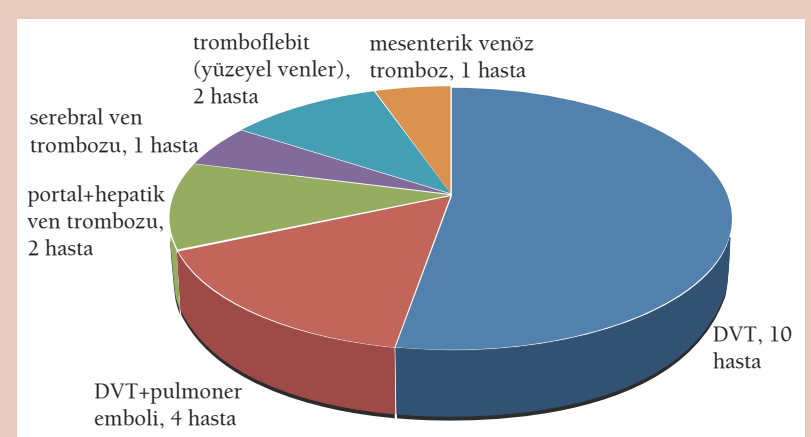

Şekil 1. Trombozların izlenme bölgeleri. DVT: Derin ven trombozu

duğu için yorum yapılamadı. Tromboz öyküsü olan hastaların 7 tanesinde cerrahi müdahale öyküsü vardı. Bu hastaların 4 tanesinde tromboz cerrahi sonrası ortanca 2 ay (1-4) sonra ortaya çıkarken 2 hastada cerrahi sonrası tromboz geliştiği görüldü. Antikoagülasyon tedavisi olarak 9 hastada düşük molekül ağırlıklı heparin (DMAH), 8 hastada warfarin, 1 hastada ise rivaroksaban tedavisi verildiği izlendi; 2 hastanın aldıkları antikoagülasyon tedavi bilgisine ulaşılamadı. Ortanca antikoagülasyon süresi ise 2,75 (1-120) ay olarak bulundu. Antikoagülasyon tedavisi altında hiçbir hastada gastrointestinal sistem kanaması olmadı (Tablo 2).

Tromboz izlenen hastaların tromboz tanısı esnasında aldıkları tedaviler ile güncel tedavileri arasında önemli farklılıklar vardı. 20 hastanın 13 tanesinde tromboz tanısı sonrası aldıkları medikal tedavilerde bir üst basamağa geçiş görüldü. 5-amino salisilik asit (ASA) alan hastalara azatiyopürin, steroid ve/veya anti-tümör nekrozis faktör (TNF) başlanmıştı. Ilaç almayan hastalara ise takiplerde 5-ASA, anti-TNF ve/veya azatiyopürin verilmişti. Tromboz oluşan hastaların güncel tedavilerine bakıldığında 4 hastada anti-TNF tedavisi verildiği görüldü. $\mathrm{Bu}$ hastaların sadece bir tanesi tromboz tanısı esnasında anti-TNF alırken diğer üç hasta tromboz oluştuktan sonra anti-TNF kulanmaya başlamışlardı.

\section{TARTISSMA}

Çalışmamız literatürle uyumlu olarak trombozların en sık bacak derin venlerinde geliştiğini göstermiştir. Bununla beraber trombozlar farklı vasküler yataklarda da oluşabilir. Çoğu hastamızda trombozların aktif hastalık esnasında oluşması inflamasyonun tromboz etiyopatogenezinde rol aldığını düşündürmektedir. Yine tromboz gelişen hastalarımızın çoğunda takiplerde mevcut tedavilerinin yerine bir üst basamak tedaviye geçilmiştir. Bu sonuç tromboz gelişen IBH'nın ciddi seyirli olabileceğini ve bu hastaların daha yakın takip edilmesinin gerekebileceğinin bir işareti olabilir. Tromboz gelişen IBH'da antikoagülasyon amaçlı DMAH ve warfarin güvenle kullanılabilir.

Inflamatuvar barsak hastalıkları normal populasyona göre artmış tromboz riskiyle beraberdir (5). İH'da tromboz riskinde artışın kesin nedeni belli değildir. Bununla beraber kazanıl- mış ve genetik faktörlerin beraber etkisiyle bu risk artışının oluştuğu görülür. Kazanılmış faktörlerden olan sigara içimi, steroid kullanımı, immobilizasyon, inflamasyon ve cerrahi gibi durumlar IBH'da sik olup tromboza zemin hazırlayabilirler (6). Normal popülasyonda tromboza zemin hazırladığı iyi bilinen Faktör 5 Leiden mutasyonu ve protrombin G20210A mutasyonu gibi herediter faktörlerin IBH'da da farklı sıklıklarda var olduğu düşünülmüş ve bunlarla ilgili farklı çalışmalar yapılmıştır (7). Trombotik öyküsü olan IBH'da Faktör V leiden mutasyonunun sıklığının arttığını gösteren çalışmalar olduğu gibi tromotik öyküsü olan hastalarda Faktör V Leiden allelinin prevalansını düşük bulan çalışmalar da vardır (8-10). Inflamasyon ve endotelyal disfonksiyon tromboza zemin hazırlayabilen diğer etiyolojik nedenlerdir. Kronik inflamasyonla ilişkili vasküler endotelyal disfonksiyon IBH'da tromboz ve ateroskleroza zemin hazırlar (11). Son olarak operasyonlar da IBH'da tromboz oluşması için risk faktörü olup post-operatif dönemde İBH'da tromboz riski artmaktadır (12).

Trombozlar IBH'da arteryel ve/veya venöz sistemde gelişebilir (13). Bununla beraber trombozlar en sik bacak derin venlerinde ve pulmoner vasküler yatakta oluşur. Venöz trombozların görülme sıklığı metaanalizlere göre IBH'da iki kat artar (14). Trombozlar venöz sistemde retinal venlerde, portal vende, hepatik venlerde ve mesenterik venlerde de nadir de olsa izlenebilir $(15,16)$. Trombozlar arteryel sistemde venöz sisteme göre daha az sıklıkta olmakla beraber görülebilirler. Arteryel yatakta aortada, retinal arterlerde, renal arterlerde, koroner, karotis ve iliak arterlerde trombozlar oluşabilir $(17,18)$.

Inflamatuvar barsak hastalıklarında trombozların tedavisi tromboz oluşmaması için profilaktik tedavi ve oluşan trombozlar için verilen antikoagülasyon tedavisinden oluşur. Özellikle aktif dönemdeki IBH'da trombozlara meyil olduğu iyi bilinir. Inflamasyonla beraber trombositoz bu hastalarm tromboz açısından risk altında olduğunu gösterir. Hastaneye yatırılarak tedavi alma gereksinimi olan IBH'da profilaksi önerilmektedir (19). Profilaktik tedavide ise önerilen ajan düşük molekül ağırlıklı heparinlerdir (DMAH). Tromboz tanısı almış IBH'da ise tedavi IBH olmayan hastalarla benzer olup sıklıkla DMAH, warfarin veya rivaroksaban kullanılmaktadır. $\mathrm{Bu}$ ajanların tedavide kullanım süreleri ise tartışmalı olup 3 aydan hayat boyu tedaviye kadar değişebilir. Aktif hastalık esnasinda tanı alan trombozlarda tedavi en az remisyon olana kadar devam etmeliyken aktif hastalık yokluğunda ortaya çıkan trombozlarda ise hayat boyu tedavi önerilmektedir (20). Yine de tedavi süresine hasta bazında karar verilmesi daha doğru gibi görülmektedir.

Sonuç olarak İH tromboza zemin hazırlayan bir hastalıktır. Tromboz gelişen hastaların erken tanı ve tedavisi morbidite ve hatta mortalitede azalmaya neden olacaktır. Aktif hastalık özellikle pretrombotik bir durum olarak değerlendirilmeli ve gerekli antikoragülasyon başlanmalıdır. 


\section{KAYNAKLAR}

1. Colìa R, Corrado A, Cantatore FP. Rheumatologic and extraintestinal manifstations of inflammatory bowel disease. Ann Med 2016;16:1-9.

2. Talbot RW, Heppell J, Dozois RR, et al. Vascular complications of inflammatory bowel disease. Mayo Clin Proc 1986;61:140-5.

3. Graef V, Baggenstoss AH, Sauer WG, et al. Venous thrombosis in non-specific ulcerative colitis. A necropsy study. Arch Intern Med 1965;117:377-82.

4. Owczarek D, Cibor D, Głowacki MK, et al. Inflammatory bowel disease: epidemiology, pathology and risk factors for hypercoagulability. World J Gastroenterol 2014;20:53-63.

5. Fumery M, Xiaocang C, Dauchet L, et al. Thromboembolic events and cardiovascular mortality in inflammatory bowel diseases: a meta-analysis of observational studies. J Crohns Colitis 2014;8:469-79.

6. Danese S, Papa A, Saibeni S, et al. Inflammation and coagulation in inflammatory bowel disease: The clot thickens. Am J Gastroenterol 2007;102:174-86.

7. Tsiolakidou G, Koutroubakis IE. Thrombosis and inflammatory bowel disease-the role of genetic risk factors. World J Gastroenterol 2008;14:4440-4.

8. Koutroubakis IE, Sfiridaki A, Mouzas IA, et al. Resistance to activated protein $C$ and low levels of free protein $S$ in Greek patients with inflammatory bowel disease. Am J Gastroenterol 2000;95:190-4.

9. Spina L, Saibeni S, Battaglioli T, et al. Thrombosis in inflammatory bowel diseases: role of inherited thrombophilia. Am J Gastroenterol 2005;100:2036-41

10. Oldenburg B, Van Tuyl BA, van der Griend R, et al. Risk factors for thromboembolic complications in inflammatory bowel disease: the role of hyperhomocysteinaemia. Dig Dis Sci 2005;50:235-40.
11. Roifman I, Sun YC, Fedwick JP, et al. Evidence of endothelial dysfunction in patients with inflammatory bowel disease. Clin Gastroenterol Hepatol 2009; 7:175-82.

12. Merrill A, Millham F. Increased risk of postoperative deep vein thrombosis and pulmonary embolism in patients with inflammatory bowel disease: a study of National Surgical Quality Improvement Program patients. Arch Surg 2012;147:120-4.

13. Landman C, Nahon S, Cosnes J, et al. Portomesenteric vein thrombosis in patients with inflammatory bowel disease. Inflamm Bowel Dis 2013;19:582-9.

14. Yuhara H, Steinmaus C, Corley D, et al. Meta-analysis: the risk of venous thromboembolism in patients with inflammatory bowel disease. Aliment Pharmacol Ther 2013;37:953-62.

15. Mantaka AN, Samonakis DN, Liontiris M, et al. Ulcerative colitis and Budd-Chiari syndrome: which comes first? Eur J Gastroenterol Hepatol 2014;26:1306

16. Abdul-Rahman AM, Raj R. Bilateral retinal branch vascular occlusion-a first presentation of crohn disease. Retin Cases Brief Rep 2010;4:102-4.

17. Szychta P, Reix T, Sevestre MA, et al. Aortic thrombosis and ulcerative colitis. Ann Vasc Surg 2001;15:402-4.

18. Novacek G, Haumer M, Schima W, et al. Aortic mural thrombi in patients with inflammatory bowel disease: report of two cases and review of the literature. Inflamm Bowel Dis 2004;10:430-5.

19. Geerts WH, Bergqvist D, Pineo GF, et al. Prevention of venous thromboembolism: American College of Chest Physicians Evidence-Based Clinical Practice Guidelines (8th Edition). Chest 2008;133:381S-453S.

20. Nguyen GC, Bernstein CN. Duration of anticoagulation for the management of venous thromboembolism in inflammatory bowel disease: a decision analysis. Am J Gastroenterol 2013;108:1486-95. 